\title{
ANTI-INFLAMMATORY EFFECT OF DICLOFENAC-SODIUM OINTMENT (CREAM) IN TOPICAL APPLICATION
}

\author{
Kohei KYUKI, Tomohisa SHIBUYA, Kaito TSURUMI \\ and Hajime FUJIMURA \\ Department of Pharmacology, Gifu University School of Medicine. \\ 40 Tsukasamachi, Gifu 500, Japan
}

Accepted September 16, 1982

\begin{abstract}
This study was performed to develop a topical ointment of diclofenac- Na which has a potent anti-inflammatory activity by oral administration. At first, research was carried out on the ointment base which influences the external anti-inflammatory effect of the drug. Ointments of diclofenac- $\mathrm{Na}$ were prepared with three kinds of bases: lipophilic, emulsion (cream) and gel bases; and their anti-inflammatory effects were compared. The cream was found to have the most potent effect. Therefore, in the next experiment, an optimum concentration of diclofenac- $\mathrm{Na}$ in cream was determined comparing the anti-inflammatory effect among the cream preparations containing 0.5 . $0.75,1.0$ and $1.5 \%$ of the drug. Obvious effects were observed with the cream containing $1.0 \%$ and $1.5 \%$ of the drug concentration, and there was no significant difference in the anti-inflammatory activities of these two concentrations. Based on these results, the cream preparation containing $1.0 \%$ of diclofenac- $\mathrm{Na}$ (DF cream) was adopted as the external ointment of the drug. The anti-inflammatory effect of this cream was compared with that of existing anti-inflammatory ointments, i.e., indomethacin gel (IM gel). bufexamac cream (BM cream) and mobilat ointment (ML ointment). DF cream produced obvious inhibition on increased vascular permeability and on acute edema and remarkable suppression of ultraviolet erythema. These activities of DF cream were similar to those of IM gel and more potent than those of BM cream and $M L$ ointment. The inhibitory effect of DF cream on the proliferation of granulation tissue was almost equal to that of $M L$ ointment and more distinguishable than that of $\mathrm{IM}$ gel and BM cream. In adjuvant arthritis, DF cream reduced the swelling ramarkably in the treated paw and slightly in the untreated paw. The anti-adjuvant activity of DF cream was equal to that of IM gel and more potent than that of $B M$ cream and $M L$ ointment. In pain to pressure stimulation. an analgesic effect was observed in the early stage of DF cream application, and its activity was slightly stronger than that of the other ointments. These results show that DF cream has an obvious anti-inflammatory effect as an external preparation, and the activity is comparable or superior to that of similar existing anti-inflammatory ointments. This cream may be considered as useful in the clinical field as a topical anti-inflammatory preparation.
\end{abstract}

Various non-steroidal anti-inflammatory drugs (NSAID) have been used clinically, but use of these drugs is sometimes restricted due to side effects. Particularly, gastrointestinal disorder is inevitable. Many efforts have been made to avoid these adverse reactions. The efforts include development of new compounds and also preparational improvement of existing drugs, i.e.. change in the administration route to suppository, arrangement in drug design such as a slow release agent (1), and device of prodrug (2). 
Topical application is also included, though the bioavailability of an external preparation had not been studied satisfactorily. Application of the drug on the diseased site or the neighboring part is reasonable since drugs produce effects after they reach the affected site. However, only steroids have been used as the topical anti-inflammatory agent because the actions of NSAID are relatively mild, and moreover, it has been thought that topical application of NSAID scarcely influenced the muscle or joint due to bad absorption from the normal skin. On the other hand, it has been revealed from a number of recent studies that NSAID are absorbed rather well from normal skin (3) and diffuse into subcutaneous soft tissue under the topically applied site (4). Thus, it became desirable to use NSAID in topical preparation as well as in systemic ones, and ointments of some NSAID are on the market already. These situations stimulated us to plan the development of a topical preparation for diclofenac-Na which produces an excellent anti-inflammatory effect in systemic use. Basic investigations were made regarding the ointment base and optimun concentration, and $1 \%$ diclofenac$\mathrm{Na}$ cream was selected as the topical preparation. The anti-inflammatory effect of this preparation was compared with that of some existing NSAID ointments.

\section{Materials and Methods}

\section{Materials}

\section{Screening of the base for external diclo- fenac-Na ointment}

To select the most suitable base for the external ointment, the following three samples were tested: 1) $1 \%$ diclofenac- $\mathrm{Na}$ ointment using a lipophilic base (DF ointment in the following description). 2) $1 \%$ diclofenac- $\mathrm{Na}$ ointment using an emulsion base (o/ $w$ type) (DF cream). 3) $1 \%$ diclofenac- $\mathrm{Na}$ ointment using carboxyvinyl polymer (DF gel).

2. Screening of the optimum concentration

\section{of DF cream}

DF creams which contained $0.5,0.75,1.0$ and $1.5 \%$ of diclofenac- $\mathrm{Na}$ were examined to establish the optimum concentration of the drug in the cream preparation. All the samples used in the sections 1 and 2 were prepared by and offered to us by CIBA-GEIBY (Japan) Ltd.

\section{Existing NSAID ointments for comparative drugs}

The following materials available on the market were used as comparative drugs. 1) Bufexamac cream (BM cream: Anderm cream. $5 \%$ bufexamac cream using emulsion base $0 / w$ type. Lederle Japan). 2) Indomethacin gel ointment (IM gel: Inteban ointment, $1 \%$ indomethacin gel using carboxyvinyl polymer base. Sumitomo Chemical Industry). 3) Mobilat ointment (ML ointment: Ointment containing $1.0 \%$ adrenal extract, $0.2 \%$ anti-thrombin heparin-like substance and $2.0 \%$ salicylic acid and using hydrophilic base, Maruho Co., Ltd.).

\section{Animals}

Experiments were carried out in dd-strain mice, Wistar or Sprague-Dawley rats and Hartley white guinea pigs. These animals were fed and kept under controlled conditions in an air-conditioned room $\left(22 \pm 2^{\circ} \mathrm{C}\right)$ after purchase from Kitayama Labes Co., Ltd: and only healthy animals were used for the study. Body weight, sex and the numbers of the used animals are described in the methods section which follows

\section{Methods}

1. Inhibition of increased vascular permeability

Each group consisted of 8 male Wistar rats weighing about $140 \mathrm{~g}$. On these animals. three points were marked on the median line of the depilated dorsal skin. where $50 \mathrm{mg}$ of the test ointment was rubbed carefully for 1 min on a circular area with a $2 \mathrm{~cm}$ diameter with each point. The ointment was applied twice, 1 and $2 \mathrm{hr}$ before a phlogogenic 
substance was given. As a phlogogenic substance, histamine $(100 \mu \mathrm{g} / 0.1 \mathrm{ml} / \mathrm{site})$ was intracutaneously injected at the center of the ointment-applied site. Immediately after the injection, 2\% pontamine sky blue solution was intraveneously injected in a volume of $0.2 \mathrm{ml} / 100 \mathrm{~g}$. After $20 \mathrm{~min}$, the rats were sacrificed, and the skin was stripped off. The blue-stained phlogogen-injected site was traced from the inner site for measurement of the area using planimeter.

\section{Inhibition of edema}

1) Inhibition of carrageenin-induced skin edema (Punch method): Each group consisted of 7 male Wistar rats weighing about $140 \mathrm{~g}$. The animals were depilated of the dorsal hair, where two points were marked symmetrically on both sides of the median line. On the two points of one side, $50 \mathrm{mg}$ of the test ointment was carefully rubbed for $1 \mathrm{~min}$ at 1 and $2 \mathrm{hr}$ before intracutaneous injection of carrageenin ( $1 \% .0 .1 \mathrm{ml} / \mathrm{site}$ ). On the two points of the other side, only physiological saline solution $(0.1 \mathrm{ml} / \mathrm{site})$ was injected without pretreatment. After $2 \mathrm{hr}$, the rats were sacrificed, and the skin was stripped off. A $16 \mathrm{~mm}$ circle of skin from the injected site was removed using a puncher for leather, and the weight of the punched-skin was measured. The ratio of weight gain at the phlogogen-injected site to the saline-treated site (edema rate) was calculated.

2) Inhibition of carrageenin-induced paw edema: Each group consisted of 8 male Wistar rats weighing about $130 \mathrm{~g}$. The volumes of the unilateral hind paws of these animals were measured: and on each paw. test ointment was carefully rubbed twice at 1 and $2 \mathrm{hr}$ before the carrageenin was given. This ointment-treated part was covered softly with in order to prevent the rats from licking off the ointment. Then, carrageenin $(1 \%, 0.1 \mathrm{ml})$ was injected subcutaneously into the paw, and the volume of the hind paw was measured hourly for $5 \mathrm{hr}$. The edema rate was calculated from the initial volume.

3) Inhibition of croton oil-induced edema in the ear (5): Each group consisted of 10 male mice weighing about $23 \mathrm{~g}$. Twenty $\mathrm{mg}$ of the test ointment was rubbed on the back of the right ear $30 \mathrm{~min}$ after $30 \mu \mathrm{l}$ of $4 \%$ croton oil ether solution was dropped on the surface of that ear. The mice were sacrificed $4 \mathrm{hr}$ after the dropping of croton oil, and the bilateral ears were cut off. Central part of the ear was punched out using a puncher with a $9 \mathrm{~mm}$ diameter and weighted. The edema rate of the right ear was calculated in comparison with the weight of the untreated left ear.

\section{Inhibition of ultraviolet erythema}

Each group consisted of 5 male guinea pigs weighing $300-350 \mathrm{~g}$. The animals were depilated of the dorso-lateral hair; and $24 \mathrm{hr}$ later, an adhesive plaster with two small holes was placed on the depilated flank where ultraviolet irradiation was applied for $40 \mathrm{sec}$ from a distance of $20 \mathrm{~cm}$ (High pressure mercury lamp by Wako Electric Physicochemical Industry). Immediately after UV-application. $100 \mathrm{mg}$ of the test ointment was rubbed carefully on the UV-applied site for $1 \mathrm{~min}$. The effect was evaluated by hourly macroscopic observations for $5 \mathrm{hr}$ and graded as follows: Score $3=a$ full circle of definite redness of any intensity, score $2=$ an area of erythema not clearly defined as a circle, score $1=$ an erythema barely observed and score $\mathrm{O}=$ no evident erythema.

\section{Inhibition of proliferation of the granu- lation tissue}

1) Paper disk method: Each group consisted of 8 male Wistar rats weighing about $150 \mathrm{~g}$. A $1.5 \mathrm{~cm}$ incision was made on the skin of these animals along the dorsal median line under pentobarbital- $\mathrm{Na}$ anesthesia, and a paper disk of $30 \pm 1 \mathrm{mg}$. which had been previously weighed and sterilized (Toyo Filters Co., Ltd.; $8 \mathrm{~mm}$ in the diameter. $1 \mathrm{~mm}$ thick). was implanted bilaterally under the 
skin of the scapular regions. Fifty $\mathrm{mg}$ of the test ointment was rubbed carefully on the normal skin over the disk-implanted site twice a day for 6 days. On the 7 th day, the rats were sacrificed. The granulation tissue that proliferated around the paper disk was carefully extracted and was weighed after drying for $24 \mathrm{hr}$ (at $40^{\circ} \mathrm{C}$ ).

2) Inhibition of wound healing: Each group consisted of 5 male guinea pigs weighing about $300 \mathrm{~g}$. The animals were depilated of the dorsal hair. On the skin, a $1.5 \mathrm{~cm}$ incision was made on both sides of the median line under pentobarbital- $\mathrm{Na}$ anesthesia, and a suture was made at the center of the incision. Fifty $\mathrm{mg}$ of the test ointment was rubbed on the incised site once a day for 5 days from the day of operation, and the suture was taken out on the 3rd day. On the 6th day, the animals were sacrificed, the dorsal skin was flayed. and a strip of the wounded part was cut off. Traction was given at the strip, and the strength to tear was measured.

\section{Inhibition of adjuvant arthritis}

In male Sprague-Dawley rats, weighing about $180 \mathrm{~g} .0 .6 \mathrm{mg} / 0.1 \mathrm{ml}$ of mycobacterium butyricum (Difco) suspended in liquid paraffin was subcutaneously injected into the plantar site of the right hind paw under ether anesthesia. The rats in which appearance of secondary inflammation was confirmed in the left hind foot, bilateral front foot and/or tail were selected: and 5 of these animals were used in each group. Then, 100 $\mathrm{mg}$ of the test ointment was rubbed on the plantar of the right hind paw once a day for 7 days. The ointment-applied part was softly covered with wrap-film, and after $5 \mathrm{hr}$, the applied part was rinsed well with warm water until no ointment remained. The edema of the bilateral hind paw was measured on the 1 st, 4 th and 7 th day.

6. Inhibition of pain to pressure stimulation Each group consisted of 10 male Wistar rats weighing about $100 \mathrm{~g}$, and the experiment was performed according to Randall and Selitto's method (6) as follows: Fifty mg of the test ointment was rubbed carefully on the plantar site of the right hind paw for 30 sec immediately after yeast $(10 \%, 0.1 \mathrm{ml})$ was subcutaneously injected into that paw. and the treated part was covered softly with wrap-film. Pressure stimulation was given every 30 min from 2 nd hr after the injection of yeast using the Analgesymeter (Ugo Basile, Milano), and the threshold of pain response was measured for $2 \mathrm{hr}$.

\section{Results}

\section{Screening of the base for external diclo- fenac-Na ointment}

Regarding topical diclofenac- $\mathrm{Na}$ ointment, the anti-inflammatory activity was compared among three kinds of base: DF ointment, DF cream and DF gel. The result is shown in Table 1. The inhibitory effect on carrageenininduced paw edema was obvious in the three samples as compared with the non-treated reference group, and the order of the inhibitory activity among the three ointment bases was the cream, gel and lipophilic ointment. The inhibitory activity of the cream was significantly stronger than that of the lipophilic ointment at the 3rd hr. Strong inhibitory activities on ultraviolet erythema were observed in the three samples, and there was no significant difference in the activity among them. Swelling in the inflamed paw of adjuvant arthritis was remarkably reduced by application of the three samples. The effect was weak with the lipophilic ointment as compared with the cream and gel on the 1st day of application (16th day after injection of adjuvant), but the difference in the effect disappeared after repeated applications. On pain threshold to pressure stimulation, an obvious increasing effect was observed with the cream and gel samples as compared with the non-treated reference until the $3 \mathrm{rd} \mathrm{hr}$, 
Table 1. Effects of three kinds of DF ointment on various models of inflammation and pain threshold

\begin{tabular}{|c|c|c|c|c|c|c|c|c|}
\hline \multirow[t]{2}{*}{$\begin{array}{l}\text { Test ointments } \\
(1 \% \text { DF })\end{array}$} & \multicolumn{2}{|c|}{$\begin{array}{l}\text { Inhibitory \% on } \\
\text { carrageenin edema1s }\end{array}$} & \multicolumn{2}{|c|}{$\begin{array}{l}\text { Inhibitory \% on } \\
\text { ultraviolet erythema } 2)\end{array}$} & \multirow{2}{*}{\multicolumn{2}{|c|}{$\begin{array}{l}\text { Inhibitory \% on } \\
\text { adjuvant arthritis } \\
\text { swelling } \\
\text { s) }\end{array}$}} & \multicolumn{2}{|c|}{$\begin{array}{l}\text { Increase } \% \text { on } \\
\text { pain threshold }\end{array}$} \\
\hline & $3 \mathrm{hr}$ & $5 \mathrm{hr}$ & $2 \mathrm{hr}$ & $5 \mathrm{hr}$ & & & $2 \mathrm{hr}$ & $3 \mathrm{hr}$ \\
\hline DF ointment & $30.6^{* * *}$ & 34.4 & * & 20. & 12 & 46. & & - \\
\hline DF cram & $50.0^{* * *}$ & $50.0^{* \cdots}$ & $82.6^{* * *}$ & $36.7^{* * *}$ & $36.8^{* *}$ & $47.4^{* * *}$ & $13.3^{*}$ & $48.7^{*}$ \\
\hline DF gel & $40.3^{* * *}$ & $37.5^{* * *}$ & $82.6^{* * *}$ & $30.0^{* * *}$ & $35.5^{* * *}$ & $49.1^{* * *}$ & $23.3^{*}$ & $35.8^{*}$ \\
\hline
\end{tabular}

1) Carrageenin edema test in rats. Test ointment $(50 \mathrm{mg})$ was applied topically 1 and $2 \mathrm{hr}$ before carrageenin $(1 \%, 0.1 \mathrm{ml})$ was given s.c. into the plantar site of the rat foot.

2) Ultraviolet erythema test in guinea pigs. Test ointment (100 $\mathrm{mg})$ was applied immediately after ultraviolet irradiation.

3) Therapeutic test on foot swelling of adjuvant-induced arthritis in rats. Test ointment (100 mg) was applied topically once a day for 7 days from the 15 th day after adjuvant treatment.

4) Test by means of Randall and Selitto's method in rats. Test ointment $(50 \mathrm{mg})$ was applied immediately after yeast $(5 \%, 0.1 \mathrm{ml})$ was given s.c. into the plantar site of the rat foot.

"P<0.05, ${ }^{*} P<0.01,{ }^{* *} P<0.001$

Table 2. Influence of concentration on effects of DF cream in various models of inflammation

\begin{tabular}{ccccccc}
\hline \multirow{2}{*}{$\begin{array}{l}\text { Test ointment and } \\
\text { concentration }\end{array}$} & \multicolumn{2}{c}{$\begin{array}{l}\text { Inhibitory \% on } \\
\text { carrageenin edema }\end{array}$} & \multicolumn{2}{c}{$\begin{array}{l}\text { Inhibitory \% on } \\
\text { ultraviolet erythema }\end{array}$} & \multicolumn{2}{c}{$\begin{array}{l}\text { Inhibitory \% on } \\
\text { croton oil ear edema1) }\end{array}$} \\
& $3 \mathrm{hr}$ & $5 \mathrm{hr}$ & $2 \mathrm{hr}$ & $5 \mathrm{hr}$ & $4 \mathrm{hr}$ \\
\hline \multirow{3}{*}{$\begin{array}{c}\text { DF cream } \\
0.5 \%\end{array}$} & 8.5 & 23.4 & $52.0^{* * *}$ & 10.0 & 17.5 \\
& $1.0 \%$ & $35.4^{* *}$ & $41.5^{* *}$ & $60.0^{* * *}$ & $23.3^{* *}$ & $22.9^{* *}$ \\
$1.5 \%$ & $39.0^{* *}$ & $39.0^{* *}$ & $80.0^{* * *}$ & $33.3^{* * *}$ & $27.3^{* *}$ \\
\hline
\end{tabular}

1) Ear edema test induced by croton oil in mice. Test ointment $(20 \mathrm{mg})$ was applied topically $30 \mathrm{~min}$ before croton oil was dropped on the ear.

* $P<0.05, " * P<0.01,{ }^{* * * P}<0.001$

and the effects of the two samples were almost equal. However, the effect on the pain threshold was not obvious with the lipophilic ointment. These results reveal the great influence of the base on anti-inflammatory effects of topical DF ointment, and a stronger effect of the cream and gel than the lipophilic ointment was observed. From the above results, we concluded that the cream was the most superior as an external DF ointment.

\section{Screening of the optimum concentration of DF cream}

The anti-inflammatory activity of DF cream was compared with DF concentrations of $0.5,0.75,1.0$ and $1.5 \%$; and the results are shown in Table 2. No obvious effect on carrageenin-induced paw edema was observed in the $0.5 \%$ cream as compared with the non-treated reference group, but an obvious effect was obtained with 0.75 , 1.0 and $1.5 \%$ DF. There was no significant difference in the effect among the three groups. The inhibitory effect of DF cream on UV-erythema was concentration-dependent. The activity of the 1.0 and $1.5 \%$ cream was significantly stronger than that of the 0.5 and $0.75 \%$ creams $(P<0.05)$, and there was no significant difference in the effect between the 1.0 and $1.5 \%$ creams. The inhibitory effect on croton oil-induced edema in the ear was not significant with the $0.5 \%$ cream, though an inclination to inhibition was observed. Obvious inhibition was obtained with the 0.75 and greater \% cream, and the effect was especially strong with the 1.0 and 


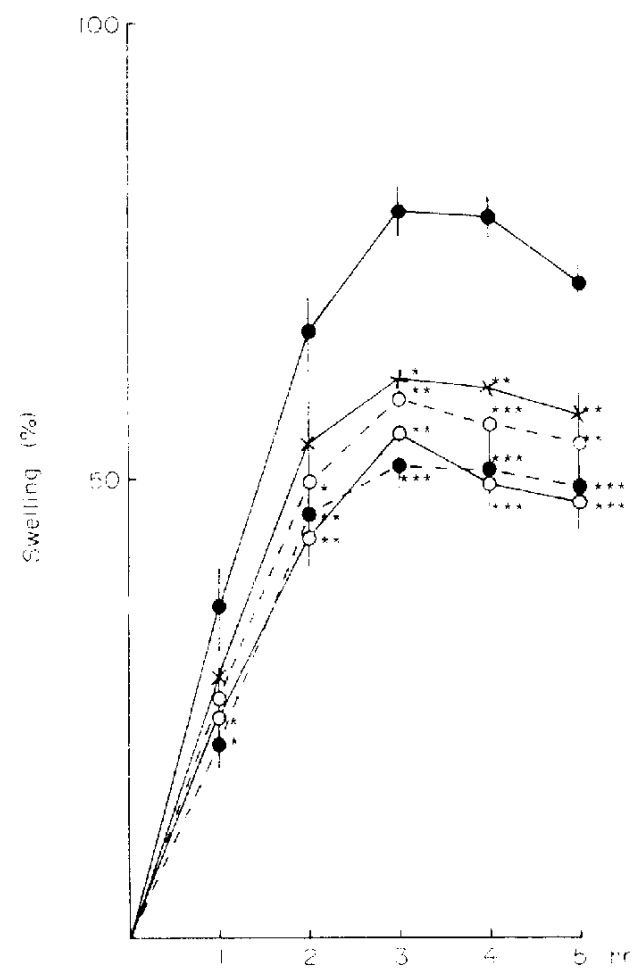

Fig. 1. Effect of topical application of DF cream and reference preparations on paw edema induced by carrageenin in rats. Test ointment $(50 \mathrm{mg})$ was applied topically 1 and 2 hr before carrageenin (1\%, $0.1 \mathrm{ml}$ ) was given s.c. into the plantar site of the rat foot. Each value represents the mean \pm S.E. of 8 male rats. The vertical bars indicate standard errors of the means. Control, $\bigcirc-O$ DF cream, $\times \longrightarrow \times$ BM cream, $O \cdots . . .0 \mathrm{OL}$ ointment

$1 \mathrm{M}$ gel BM cream (Andarm=5\% Bufexamac cream). IM gel (Inteban=1\% Indomethacin gel), ML ointment (Mobilat $=2 \%$ salicylic acid, $0.2 \%$ mucopolysaccharide polysulfuric acid ester. $1 \%$ suprarenal extract). These abbreviations are the same in all tables and figures. ${ }^{*} P<0.05 .{ }^{* *} P<0.01,{ }^{* *} P<0.001$

a potent inhibitory effect comparable to that of IM gel. The effect was obvious also in BM cream, but it was significantly weaker than those of DF cream and IM gel. The effect of $M L$ ointment was weak, and it was significant only at the 1 st hr after UV irradiation.

4) Inhibition of proliferation of the granulation tissue

a) Inhibition of proliferation of the granu-

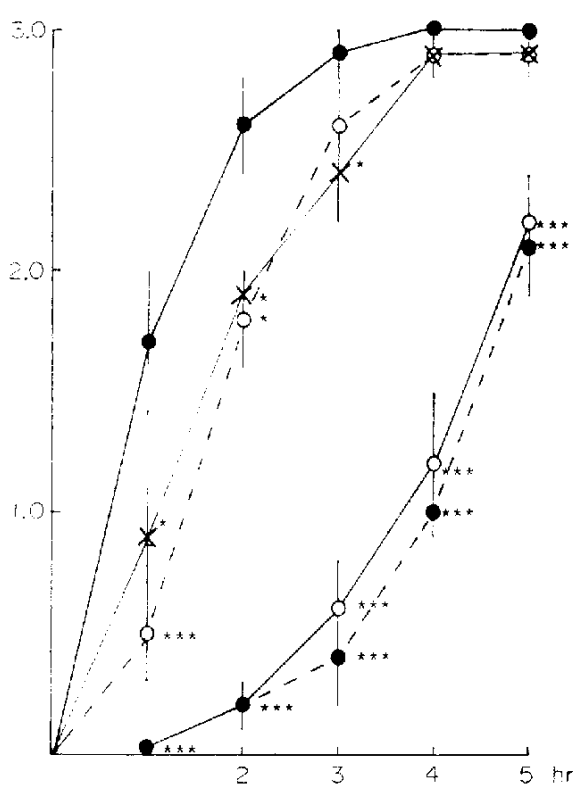

Fig. 2. Effect of topical application of DF cream and reference preparations of ultraviolet erythema on guinea pigs. Test ointment $(100 \mathrm{mg}$ ) was topically applied immediately after ultraviclet irradiation. Each value represents the mean \pm S.E. of 5 male guinea pigs. The vertical bars indicate standard errors of the means. Control. $\mathrm{O}-\mathrm{O} \mathrm{DF}$ cream, $x-\times$ BM cream,...$- .0 \mathrm{ML}$ ointment. - IM gel. ${ }^{*} P<0.01,{ }^{* *} P<0.001$.

lation tissue by paper disk method: Table 4 shows the inhibitory effect on the weight of the granulation tissue that proliferated around the paper disk implanted under the rat back skin. The effects of three comparative samples were almost equal with an inhibition rate of about $15 \%$. While DF cream had a significant stronger inhibition rate $(30 \%)$ than the others.

b) Inhibition of wound healing: Table 4 shows the inhibitory effect on the healing of the linear wound in the back skin of guinea pigs. The inhibitory effect of DF cream was potent, and that of ML ointment was even stronger. The inhibitory rate of IM gel was slightly less than that of DF cream, but there was no significant difference. Though an inclination to inhibition was also observed 
Table 4. Effects of topical application of DF cream and reference preparations on proliferation of granulation tissue

\begin{tabular}{|c|c|c|c|c|}
\hline \multirow[b]{2}{*}{$\begin{array}{l}\text { Test } \\
\text { ointments }\end{array}$} & \multicolumn{2}{|c|}{ Filter paper method"s } & \multicolumn{2}{|c|}{ Wound healing') } \\
\hline & $\begin{array}{l}\text { Dry wt. (mg) of } \\
\text { granulation tissue } \\
\text { Mean } \pm S . E \text {. }\end{array}$ & $\begin{array}{l}\text { Inhibitory } \\
\%\end{array}$ & $\begin{array}{l}\text { Tensile strength }(g) \\
\text { Mean } \pm S, E \text {. }\end{array}$ & $\underset{\%}{\text { Inhibitory }}$ \\
\hline Control & $78.5 \pm 4.2$ & & $255.8 \pm 35.1$ & \\
\hline DF cream & $54.6 \pm 3.4^{* *}$ & 30.4 & $105.6 \pm 14.7^{* *}$ & 58.7 \\
\hline BM cream & $68.1 \pm 1.3^{*}$ & 13.2 & $210.9 \pm 34.8$ & 17.6 \\
\hline ML ointment & $64.4 \pm 2.1^{* *}$ & 18.0 & $98.8 \pm 11.0^{* *}$ & 61.4 \\
\hline IM gel & $65.8 \pm 2.0^{* *}$ & 16.2 & $137.6 \pm 22.0^{* *}$ & 46.2 \\
\hline
\end{tabular}

1) Test on proliferation of granulation tissue around a filter paper implanted in rats. Test ointment (50 $\mathrm{mg}$ ) was applied topically twice a day for 6 days after implantation of the paper disk.

2) Wound healing test in guinea pig skin. Test ointment $(50 \mathrm{mg})$ was applied once a day for 5 days.

${ }^{*} \mathrm{P}<0.05,{ }^{*} \mathrm{P}<0.01$

with BM cream, the effect was not significant

\section{5) Inhibition of adjuvant arthritis}

Figures 3 and 4 show the changes in the swelling rate of the treated right hind paw and that of the non-treated left hind paw. respectively. DF cream reduced the swelling remarkably in the right hind paw, and the effect was comparable to that of IM gel. Changes in the swelling rate were hardly observed with BM cream and $M L$ ointment, though their inhibitory effects were significant as compared with the control. In the nontreated hind paw, DF cream and IM gel reduced the swelling slightly, and the effect was obvious in comparison with the reference group in which swelling augmented with the day. Similar results were obtained with ML ointment and BM cream, though their effects were somewhat weak as compared with that of DF cream.

6) Inhibition of pain to pressure stimulation

Figure 5 shows the effect on the pain threshold in yeast-induced foot swelling. An obvious effect was observed with DF cream as compared with the control in the early stage. Effects were also obtained with $I M$ gel and $M L$ ointment, though they were slightly weaker than that of DF cream, while BM cream produced only an inclination to inhibition in the early stage.

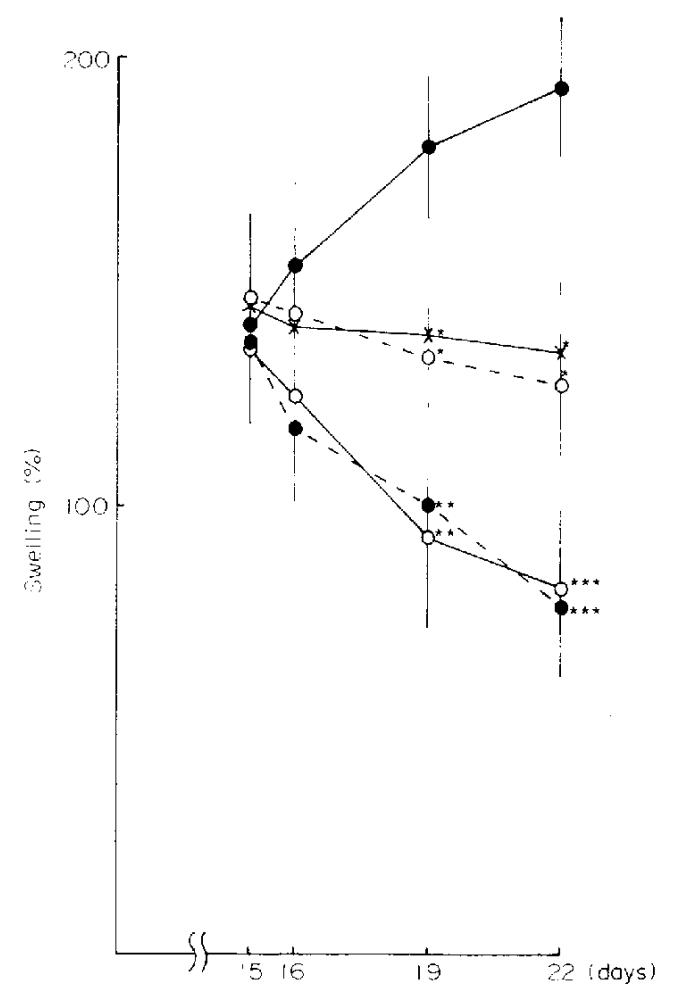

Fig. 3. Effect of topical application of DF cream and reference preparations on swelling of rat right hind paw (treated foot) induced by adjuvant arthritis. Test ointment (100 mg) was applied topically once a day for 7 days. Each value represents the mean \pm S.E. of 5 male rats. The vertical bars indicate standard errors of the means.

Control. O--O DF cream, $\times-\times$ BM cream. $\bigcirc$ … ML ointment, 1 ...... $\mathrm{IM}$ gel. ${ }^{*} \mathrm{P}<0.05$. ${ }^{* *} \mathrm{P}<0.01,{ }^{* * *} \mathrm{P}<0.001$. 


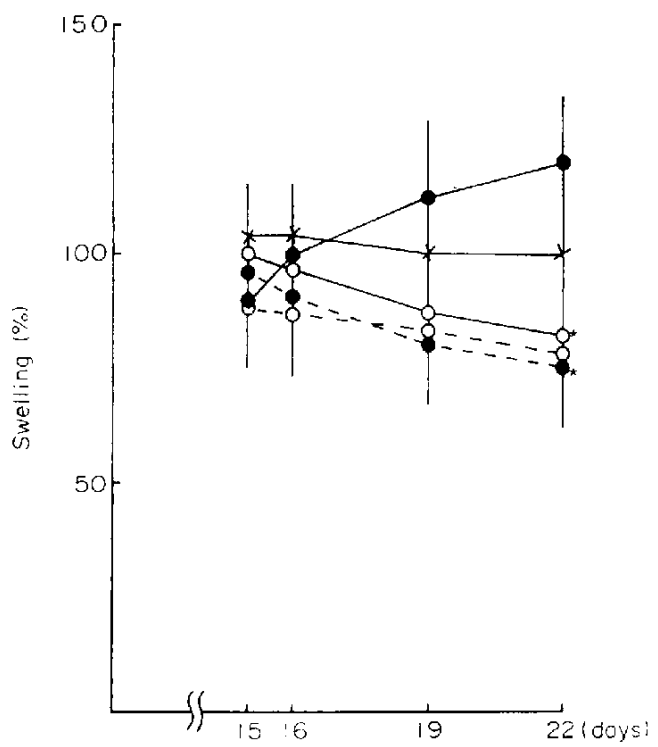

Fig. 4. Effect of topical application of DF cream and reference preparations on swelling of rat left hind paw (untreated foot) induced by adjuvant arthritis. Test ointment (100 mg) was applied topically once a day for 7 days. Each value represents the mean $\pm S$.E. of 10 male rats. The vertical bars indicate standard errors of the means.

Control, O-O DF cream, $\times-\times$ BM cream. $\bigcirc$ ○ ML cintment. $1 \mathrm{M}$ gel. ${ }^{*} \mathrm{P}<0.05$

\section{Discussion}

Most anti-inflammatory agents for topical application have been limited to steroids till the present time. Systemic side effects appeared with steroids even in topical application $(7,8)$ so that ample attention is required for their usage. On the other hand. gastro-intestinal disorders have restricted the clinical use of oral NSAID. Under these circumstances, it is considered that the external NSAID preparation is a highly useful drug design for a disease in which topical treatment is possible, and some external ointments of NSAID have been developed ( 9 11). DF is one of the NSAID which produces a potent anti-inflammatory effect by oral administration. The inhibitory activity of oral DF on acute and chronic inflammatory reactions was slightly weaker than that of IM,

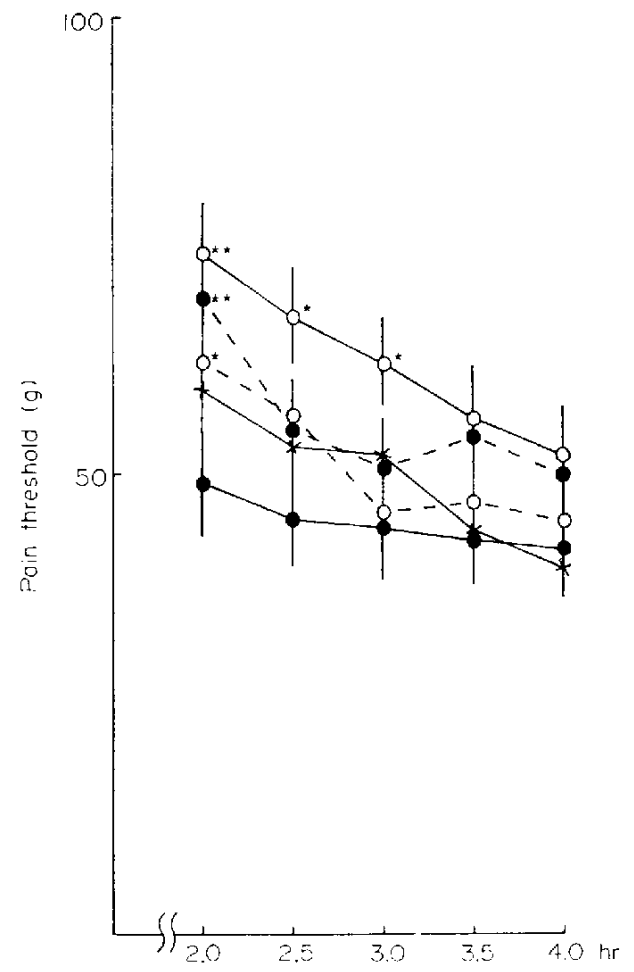

Fig. 5. Analgesic effect of topical application of DF cream and reference preparations by means of Randall and Selitto's method in rats. Test ointmen: (50 mg) was topically applied immediately after yeast $(5 \%, 0.1 \mathrm{ml})$ was given s.c. into the plantar site of the rat foot. Each value represents the mean $\pm S$. E. of 10 male rats. The vertical bars indicate standard errors of the means. Control, O-O DF cream, $\times-\times$ BM cream, $O \cdots O$ ML ointment. - ...... IM gel. "P<0.05. " $P<0.01$.

but more potent than that of phenylbutazone (12). Therefore, development of an external ointment was planned for DF. Some factors seem to influence the effect of external NSAID, and one of the most influential manufactural factors is the ointment base (13). First three preparations of DF ointment using different bases were made in order to select the base with which the most definite anti-inflammatory effect was obtained. Next, the optimum concentration of DF in the base which was selected in this preliminary study was established. Then, the anti-inflammatory effect of the sample which was prepared 
with the base selected and the optimum concentration of DF was compared with those of existing external preparations, IM gel, BM cream and $M L$ ointment. Though the evaluation method of the effect of the ointment is basically the same as that of systemic treatment, some restrictions peculiar to external agents exist in experimental procedures, i.e. techniques for restraining the animal to prevent them from licking the ointment. Authors have made various studies on these matters and reported the experimentation on anti-inflammatory activity of topical agents (14). This study was carried out using such a type of experimentation.

At first, to study the influence of the ointment base on the effect, the antiinflammatory effects of three kinds of external DF ointment, using lipophilic, emulsion (cream) and gel bases, were compared. Among them, the cream and gel preparations had potent effects globally as compared with the preparation with the lipophilic base. We considered that the effect of the cream was the most superior and stable. On the other hand, there are both topical preparations of an ointment with a lipophilic base and a cream with an emulsion base in BM. Though the detailed results were not shown in this paper, we proved a distinguishably stronger activity of the cream in the comparison between them. Based on these evidence, the cream base was also employed for the DF ointment. In the following experiment, the effect of DF cream was compared among DF concentrations of $0.5,0.75,1.0$ and $1.5 \%$. All effects tested were weak in the $0.5 \%$ cream, except for the inhibitory effect on UV erythema. To the contrary, significant inhibitory effects on all the tested models of inflammation were observed with the preparations containing 0.75 and greater $\%$ of $D F$, and the effects were especially definite in the 1.0 and $1.5 \%$ preparations. There was a small difference in the inhibitory rate between these 1.0 and $1.5 \%$ preparation, but it was not significant. Therefore, we concluded that the optimum concentration of DF cream was $1.0 \%$. Based on these experiments, the $1.0 \%$ preparation using a cream base, called DF cream. was employed as an external DF ointment: and in this study, the effect of this preparation was compared with that of some existing anti-inflammatory ointments.

DF cream had significant inhibitory effect on increased vascular permeability induced by histamine, and the activity was almost comparable to that of $\mathrm{BM}$ cream and $\mathrm{ML}$ ointment and was slightly weaker than that of IM gel. Edema reaction secondary to the increased vascular permeability was examined in the carrageenin-induced reactions and in the croton oil-induced reaction. DF cream produced a potent inhibitory effect on these edema. The activity was equal or superior to the existing ointments on carrageenininduced paw edema and on croton oilinduced edema. Moreover, the inhibitory rate of DF cream was highest against carrageenin-induced skin edema. In addition, DF cream also produced potent inhibition on UV erythema, comparable to IM gel. As compared with those drugs, the antierythemic activities of BM cream and $\mathrm{ML}$ ointment were weak. These results proved that DF cream produced a potent antiinflammatory activity on acute inflammatory reaction which was comparable or superior to the existing anti-inflammatory ointments.

Influence on the proliferation of granulation tissue was examined using the implanted filter paper method. The potent inhibitory effect was observed with DF cream, and its activity was highest among the tested ointments. In direct application onto the surface of the wounded area, DF cream obviously prolonged the wound healing. Strength of the effect followed that of $\mathrm{ML}$ ointment which contained the adrenal cortex 
extract. The inhibitory rate was small in IM gel as compared with DF cream, though the difference was not significant. The inhibitory effect itself was not significant in BM cream. These results show the obvious inhibitory effect of DF cream on proliferation of the granulation tissue, comparable to the effect of ML ointment which contains steroids and is accepted to produce inhibition of proliferation of the granulation tissue. In adjuvant arthritis, one of the disease models of chronic rheumatoid arthritis, DF cream strongly inhibited swelling in the treated hind paw as well as IM gel. The effects of BM cream and ML ointment were weaker as compared with those of DF cream and $I M$ gel, though there was also no significant difference. A similar effect was obtained in the non-treated hind paw, but it was slight as compared with the treated side. Percutaneous absorption of drug appears to be better in damaged skin than in normal skin because the stratum corneum in inflamed skin is destroyed, and the barrier system is missing (15). As swelling of treated hind paw in adjuvant arthritic rats is marked and skin is damaged, it may be considered that NSAID ointment by topical application inhibit markedly the treated paw edema due to high absorption. In the last experiment, it was revealed that DF cream produced an obvious inhibitory effect on pain to pressure stimulation in the early stage of the application. though the effect promptly disappeared with time. Similar but slightly weaker effects were obtained in IM gel and ML ointment. Based on these results, it can be concluded that topical application of DF cream produced obvious inhibitory effects on acute, subacute and chronic inflammatory reactions, proving the efficacy of the drug as an external preparation.

\section{References}

1) Mizushima, Y.: Classification and selection of nonsteroidal anti-inflammatory drugs. Medicine and Drug Journal 15, 39-43 (1979) (in Japanese)

2) Tsurumi, K.: General consideration and possibility of prodrug. Medicine and Drug Journal 16, 1119-1123 (1980) (in Japanese)

3) Kimata, H., Matsumoto, O., Koide, T., Inaki, T. and Ishihama, H.: Percutaneous absorption of indomethacin. Basic Pharmacology and Therapeutics 7, 21-27 (1979) (in Japanese)

4) Ishihara, H., Kimata, $H$. and Mizushima, $Y$ :: Percutaneous penetration of indomethacin. Experientia 35, 798-799 (1979)

5) Tonelli, G., Thibault, L. and Ringler, I.: A bioassay for the concomitant assessment of the antiphlogistic and thymolytic activities of topically applied corticoids. Endocrinology 77. 625-634 (1965)

6) Randall, L.O. and Selitto, J.J.: A method for measurement of analgesic activity on inflamed tissue. Arch. Int. Pharmacodyn. Ther. 111, 409419 (1957)

7) Shimao, S.: Problems regarding side effects of corticoid therapy in the field of dermatology. The Nishiniton Journal of Dermatology 40 , 5-24 (1978) (Abs. in English)

8) Harada, T. and Takeda, K.: Percutaneous effect of topically applied $0.025 \%$ beclomethasone dipropionate cream on the adrenocortical function. The Nishiniton Journal of Dermatology 40, 924-932 (1978) (Abs. in English)

9) Fujimura, H., Tsurumi, K. and Kyuki, K.: Antiinflammatory activity of butyl-2-3-(trifluoromethyl) phenyl amino benzoate (HF-264) by topical application. Pharmacometrics 17, 10331042 (1979) (Abs. in English)

10) Hayakawa, R., Ueda, H. and Isawa, Y.: Clinical effect of topical anti-inflammatory preparation (HF-264 ointment). Hifu 22, 477-486 (1980) (Abs. in English)

11) Amachi, T., Iwabuchi, Y., Kamo, Y., Yoshida, T., Ota, M., Uragami, Y., Tanno, R., Motomura, S., Sugiyama, E., Urano, Y., Matsunaga, D. and Ogawa, Y.: Double blind test of indomethacin ointment. Basic Pharmacology and Therapeutics 7, 69-89 (1979) (in Japanese)

12) Tsurumi, K., Hiramatsu, Y., Nozaki, M., Hayashi, M., Shibuya, T. and Fujimura, H.: Anti-inflammatory action of $\mathrm{N}$-(2.6-diclorophenyl)-0amino-phenylacetic acid. its sodium salt. N(2.6-dichlorophenyl)-anthranilic acid and its sodium salt. Folia Pharmacol. Japon. 69, 299318 (1973) (Abs. in English)

13) Ishihara, M.: Studies on the vasoconstrictor activity of topical corticosteroid-especially on the influence of vehicles. The Nishinihon 
Journal of Dermatology 37, 86-95 (1975) (Abs. in English)

14) Kyuki, K.: Evaluation of nonsteroidal antiinflammatory drugs intended for use as topical anti-inflammatory drugs. Folia Pharmacol. Japon. 79, 461-485 (1982) (Abs. in English)
15) Tauber, U., Amin, M., Fuchs, P. and Speck, U.: Vergleichende Untersuchunged am menschen zur Resorption von Diflucortolonvalerianate. Betamethasone-17-valerianate, Bectomethasondipropionate und Fluocinolonacetonide. Arzneimittelforsch 26, 1492-1495 (1976) 